\title{
O problema da pobreza de experiência na formação do professor:
} desafios da educação inclusiva

Michelli Agra ${ }^{1}$

\section{RESUMO}

O presente artigo tem por objetivo discutir os desafios da educação inclusiva, com base no conceito de experiência aplicado à problemática da formação do professor. Utiliza-se como referencial teóricometodológico, a Teoria Crítica da Sociedade, com base nos autores Theodor Adorno e Walter Benjamin. As considerações giram em torno da argumentação das possíveis causas e efeitos do empobrecimento da experiência na sociedade burguesa capitalista, com a seguinte questão: 'Para que viver experiências na formação de professor?' No sentido que se procura expor, a experiência deixa marcas que passam a pertencer à subjetividade do indivíduo, além de potencializar a racionalidade e a autonomia. A educação inclusiva, por sua vez, revela a educação geral e pode contribuir para uma educação que propicie a resistência e a emancipação humana.

Palavras-chave: Experiência; Formação do Professor; Educação Inclusiva.

The problem of poverty of experience in teacher training: challenges of inclusive education

\section{ABSTRACT}

This article aims to discuss the challenges of inclusive education, based on the concept of experience applied to the problem of teacher education. The Critical Theory of Society, based on the authors Theodor Adorno and Walter Benjamin was used as theoretical-methodological reference. Considerations revolve around arguing the possible causes and effects of the impoverishment of experience in capitalist bourgeois society, with

1 Doutoranda no Programa de Pós-Graduação em Educação na Universidade Federal Fluminense/UFF, bolsista CAPES, sob orientação da Profa. Dra. Valdelúcia Alves da Costa. Mestre em Educação pelo Programa de Pós-Graduação em Educação na Universidade Federal Fluminense/UFF. Licenciatura em Educação Física pela Universidade Federal do Rio de Janeiro/UFRJ. E-mail: millissousa@yahoo.com.br 
the following question: 'Why live experiences in teacher training?' In the sense we seek to expose, experience leaves marks that pass to belong to the subjectivity of the individual, in addition to enhancing rationality and autonomy. Inclusive education, in turn, reveals general education and can contribute to an education that fosters resistance and human emancipation.

Keywords: Experience; Teacher Training; Inclusive education.

\section{El problema de la pobreza de experiencia en la formación del profesor: desafíos de la educación inclusiva}

\section{RESUMEN}

El presente artículo tiene como objetivo discutir los desafíos de la educación inclusiva, basándose en el concepto de experiencia aplicado a la problemática de la formación docente. Se utiliza como referencial teórico-metodológico, la Teoría Crítica de la Sociedad, basándose en autores como Theodor Adorno y Walter Benjamin. Las consideraciones giran alrededor de la argumentación de las posibles causas y efectos del empobrecimiento de la experiencia en la sociedad burguesa capitalista, con la siguiente cuestión: ¿Para qué vivir experiencias en la experiencia en la formación docente? En el sentido en que se busca exponer, la experiencia deja señas que pertenecen a la subjetividad del individuo, además de potenciar la racionalidad y la autonomía. La educación inclusiva, a su vez, revela la educación general y puede contribuir para una educación que favorezca la resistencia y la emancipación humana.

Palabras clave: Experiencia; Formación docente; Educación Inclusiva.

\section{Introdução}

Este artigo tem por objetivo discutir os desafios da educação inclusiva, com base no conceito de experiência aplicado à problemática da formação do professor. Entende-se a educação inclusiva como um movimento mundial de luta pela inclusão das pessoas com deficiência no sistema regular de ensino, que se fortalece a partir da elaboração da Declaração de Salamanca, em 1994.

A educação inclusiva se configura em um espaço de resistência à segregação e à marginalização historicamente imposta às pessoas 
com deficiência. Vale ressaltar que a inclusão não é um processo que se restringe às pessoas com deficiência, e sim, uma luta pela afirmação dos direitos das minorias (negros, ciganos, moradores de rua, dentre outros) à inclusão educacional, social, cultural e em todas as esferas da vida humana. Crochík et al (2011, p. 196) afirmam que a implantação da educação inclusiva torna-se relevante ao se almejar uma sociedade justa, porém é preciso considerar os limites da educação atual, no que diz respeito à formação, devido às próprias condições objetivas. Não é suficiente incluir as minorias segregadas na escola comum. A preocupação deve ser também com "[...] a qualidade da educação e com o quanto esta atualmente contribui para formar indivíduos efetivamente críticos".

Sendo assim, no atual estágio civilizatório, pensar a formação do professor e o lugar da experiência nas práticas educacionais e na vida é se permitir rever os próprios conceitos. Com ênfase no pensamento de Theodor Adorno e Walter Benjamin, à luz da Teoria Crítica da Sociedade, torna-se central a emergência de refletir sobre o empobrecimento da experiência, tal como o desmantelamento da formação como experiência formativa. Vale ressaltar, no entanto, concordando com Crochík, J. e Crochík, N. (2011, p. 111), que:

\begin{abstract}
À época da produção dos pioneiros da Teoria Crítica da Sociedade - Adorno, Horkheimer, Marcuse, Benjamin - não se discutia a educação inclusiva, fenômeno que se desenvolveu muito a partir da década de 1990, com importantes movimentos nas décadas anteriores. Assim, não é possível extrair diretamente dessa perspectiva teórica conceitos e princípios para se pensar a educação inclusiva. Além disso, a atenção que deram à educação escolar não foi ampla, ainda que todos eles tenham se preocupado com a formação do indivíduo. Theodor W. Adorno, entre eles, foi o que mais escreveu acerca desse tema. Não obstante, é possível circunscrever algumas indicações da obra desses autores que nos permitam pensar a educação inclusiva.
\end{abstract}

Dessa maneira, refletir sobre a temática da educação inclusiva, a formação do professor e o conceito de experiência à luz da Teoria Crítica da Sociedade é o objetivo desse estudo e ao mesmo tempo se apresenta como um desafio, não de propor respostas prontas ou receitas de 'como fazer', mas sim, de manejar reflexões necessárias na sociedade de classes, sem a intenção, contudo de exaurir o assunto. Antes, o propó- 
sito é abrir-se a novos aprendizados, novas discussões e dimensões do pensamento, tendo como questão: Para que viver experiências na formação de professor? Os autores propostos podem contribuir com essa discussão.

\section{O lugar da memória no tempo e na história}

Antes de discutir propriamente sobre a experiência formativa no cotidiano do professor, é relevante, ainda que brevemente, refletir sobre alguns conceitos que norteiam o conceito de experiência, são eles: tempo, história e memória. Refletir sobre tais conceitos e perceber o lugar - ou a falta de lugar - dos mesmos na sociedade capitalista embasa o problema central deste trabalho, ou seja, o empobrecimento da experiência na formação do professor.

Segundo Adorno (2011, p. 33), o desenvolvimento da sociedade burguesa sob a égide do capital, tem como consequência a destruição do tempo, da memória e da lembrança:

[...] a memória, o tempo e a lembrança são liquidados pela própria sociedade burguesa em seu desenvolvimento, como se fossem uma espécie de resto irracional, do mesmo modo como a racionalização progressiva dos procedimentos da produção industrial elimina junto aos outros restos da atividade artesanal também categorias como a da aprendizagem, ou seja, do tempo de aquisição da experiência no oficio.

Nesses termos, torna-se claro um primeiro problema sinalizado por Adorno (2011): o tempo na sociedade capitalista para aprender é escasso. A onda da produção industrial é intensa. Tudo tem potencial para se transformar em mercadoria até mesmo a educação. É preciso produzir para manter o status quo de quem domina. Para isso, não precisa pensar. Basta obedecer. $O$ ato de pensar e a aprendizagem necessitam de tempo, porém este tempo não se configura em uma realidade no ofício do professor. Daí pode-se identificar a necessidade que os professores adquiriram ao longo da história de buscar respostas prontas. Assim, perde-se a capacidade essencial de pensar, o que retira a responsabilidade, por sua vez, de formular seu próprio fazer pedagógico. Vale ressaltar que a categoria pensar para Adorno é de extrema relevância, na medida em que é o mesmo que fazer experiências intelectuais, sendo assim, 'a edu- 
cação para a experiência é idêntica à educação para a emancipação', nas palavras do autor:

Este sentido mais profundo de consciência ou faculdade de pensar não é apenas o desenvolvimento lógico formal, mas ele corresponde literalmente à capacidade de fazer experiências. Eu diria que pensar é o mesmo que fazer experiências intelectuais. Nesta medida e nos termos que procuramos expor, a educação para a experiência é idêntica à educação para a emancipação. (ADORNO, 2011, p. 151).

'Tempo é dinheiro!' Quem nunca ouviu essa expressão? O tempo na sociedade de classes é para gerar mais e mais capital. Não há tempo para pensar, não há tempo para guardar memórias, não há tempo para lembrar, não há tempo para viver experiências. Muitas são as informações diárias, porém há carência de espaço temporal para narrar experiências. Segundo Benjamin (1987, p. 203), recebem-se toda manhã notícias do mundo todo e ainda assim, não se consegue narrar histórias que surpreendam. As pessoas continuam pobres em experiências, sobretudo porque os fatos chegam acompanhados de explicações. "Em outras palavras: quase nada do que acontece está a serviço da narrativa, e quase tudo está a serviço da informação."

Vivenciamos uma infinidade de 'coisas' 2 ao longo do dia, mas não existe tempo para viver a experiência que modifica, transforma e marca a subjetividade do indivíduo. Vale lembrar que para Benjamin existem diferenças profundas entre experiência e vivência e ainda entre memória e lembrança, à luz da concepção benjaminiana, Crochík (2011, p. 72), esclarece:

\begin{abstract}
Walter Benjamin (1989) diferencia experiência de vivência. A primeira diz respeito a algo que deixa marcas, a última não. A lembrança faz parte da experiência que não pode fazer parte do progresso: tudo se deve esquecer para que a produtividade, a eficiência, não sejam atrapalhadas. Faz, por meio de Theodor Reik, a distinção entre memória e lembrança; a primeira organiza, a última destrói, desorganiza, mas ao fazer isso traz de volta o que efetivamente teve importância para o indivíduo.
\end{abstract}

2 A palavra 'coisa' é proposital, no sentido de demarcar algo sem forma determinada, um material informativo amorfo. 
No texto de Benjamin (1987), 'Sobre o conceito da história', escrito em 1940 pouco antes de se suicidar, conforme destaca Gagnebin,


maestria com que o autor articula o tempo com e na história, mostrando que a história não existe fora do tempo. Passado e presente não estão desconectados. "Se assim é, existe um encontro secreto, marcado entre as gerações precedentes e a nossa." (BENJAMIN, 1987, p. 223). O tempo, nesse sentido, não necessariamente levará ao progresso. "A ideia de um progresso da humanidade na história é inseparável da ideia de sua marcha no interior de um tempo vazio e homogêneo." (Ibidem, p. 229).

Com isso, Walter Benjamin tece uma crítica à ideia do progresso nesse tempo homogêneo, vazio e estéril. Retoma, na tese 14, a história de um 'tempo de agora': "A história é objeto de uma construção cujo lugar não é o tempo homogêneo e vazio, mas um tempo saturado de'agoras.' (Ibidem, p. 229). A construção da história é vista pelo autor não tão somente dentro de um tempo cronológico, marcado no relógio ou no calendário, a 'consciência histórica' consiste também no entendimento da história como abertura e não fechamento.

O 'agora' pode conter o todo. “O 'agora', que como modelo do messiânico abrevia num resumo incomensurável a história de toda a humanidade, coincide rigorosamente com o lugar ocupado no universo pela história humana." (Ibidem, p. 232). O 'agora' podendo ser o todo, assume uma ideia de mosaico, no sentido da história ser resultado de processos, podendo ter, assim, o passado inserido no presente:

O tempo da história é infinito em todas as direções e não é preenchido em cada um dos seus momentos. Isso quer dizer que não há um único acontecimento empírico imaginável que tenha uma relação necessária com a situação temporal bem determinada em que ele sucede. Para o evento empírico, o tempo é apenas uma forma, mas - o que é mais importante ele não é preenchido como forma. (BENJAMIN, 2013, p. 164).

Dessa maneira, Walter Benjamin coloca em pauta a discussão da temporalidade como a articulação de tempos distintos. O tempo como duração e permanências do tempo no espaço e na memória.

3 Este prefácio encontra-se no livro: 'Magia e técnica, arte e política. Ensaios sobre literatura e história da cultura.' A referência completa se encontra no final deste trabalho. 
Nesse sentido, quando as diversas temporalidades se articulam, elas podem assegurar o poder da relação humana de uns em detrimento de outros.

Em relação ao conceito de tempo e o ofício da história nas teses sobre o conceito da história, Gagnebin $(1987$, p. 8$)$ chega à seguinte conclusão:

\begin{abstract}
[...] segundo Benjamin, a historiografia "burguesa" e a historiografia "progressista" se apoiam na mesma concepção de um tempo "homogêneo e vazio" (teses 13 e 14), um tempo cronológico e linear. Trata-se para o historiador "materialista" - ou seja, de acordo com Benjamin, para o historiador capaz de identificar no passado os germes de uma outra história, capaz de levar em consideração os sofrimentos acumulados e de dar uma nova face às esperanças frustradas -, de fundar um outro conceito de tempo, "tempo de agora" ("Jetztzeit"), caracterizado por sua intensidade e sua brevidade, cujo modelo foi explicitamente calcado na tradição messiânica e judaica. Em lugar de apontar para uma "imagem eterna do passado", como o historicismo, ou, dentro de uma teoria do progresso, para a de futuros que cantam, o historiador deve constituir uma "experiência" ("Erfahrung") com o passado (tese 16).
\end{abstract}

Assim, Benjamin não considera passado e presente como tempos estanques que estão postos e não se articulam. Adorno (2011, p. 32) no texto 'O que significa elaborar o passado' busca refletir sobre as causas que permitiram o Auschwitz, no entendimento de que o passado continua presente quando as causas que tornaram possíveis tamanha barbárie continuam existindo e salienta que "O desaparecimento da consciência da continuidade histórica na Alemanha" tem um propósito: é a tentativa de justificar o injustificável e "subtrair aos assassinados a única coisa que nossa impotência pode lhes oferecer, a lembrança.", desenhando, pois, a terrível imagem de uma 'humanidade sem memória'. Afirma que não se trata tão somente de um produto de decadência ou mesmo da reação de uma humanidade que se encontra sobrecarregada de estímulos e que não consegue mais dar conta desses estímulos. Trata-se da progressividade dos princípios burgueses e a falta de consciência disso é o que apavora.

A história sem memória padece e pode se repetir no que há de mais perverso que é a barbárie. Para Walter Benjamin (1987, p. 225), ain- 
da nas teses 'Sobre o conceito da história' é chegado o momento de pensar a história na perspectiva dos vencidos, em uma tentativa de "escovar a história a contrapelo". Quanto ao sentido e a necessidade da memória, Adorno (2011, p. 34) afirma:

Apagar a memória seria muito mais um resultado da consciência vigilante do que resultado da fraqueza da consciência frente à superioridade de processos inconscientes. Junto ao esquecimento do que mal acabou de acontecer ressoa a raiva pelo fato de que, como todos sabem, antes de convencer os outros é preciso convencer a si próprio.

Tanto para Benjamin (1987) quanto para Adorno (2011), era claro que o horror estava, principalmente, em perceber a aceitação da barbárie como algo natural. Não se tratava tão somente dos algozes, mas de todas as pessoas que permitiram o curso da história, Adorno (2011, p. 118), no texto 'Educação após Auschwitz', escreve como primeira frase: "A exigência que Auschwitz não se repita é a primeira de todas para a educação." e ao narrar um diálogo com Walter Benjamin expõe a preocupação de ambos:

Em Paris, durante a emigração, quando eu ainda retornava esporadicamente a Alemanha, certa vez Walter Benjamin me perguntou se ali ainda havia algozes em número suficiente para executar o que os nazistas ordenavam. Havia. Apesar disto a pergunta é profundamente justificável. Benjamin percebeu que, ao contrário dos assassinos de gabinete e dos ideólogos, as pessoas que executam as tarefas agem em contradição com seus próprios interesses imediatos, são assassinas de si mesmas na medida em que assassinam os outros. Temo que será difícil evitar o reaparecimento de assassinos de gabinete, por mais abrangentes que sejam as medidas educacionais. (ADORNO, 2011, p. 137).

A teoria do progresso trouxe junto desgraça, ao contrário do que se pensava na época. Nesses termos, Adorno (2011, p. 138) finaliza o texto trazendo como possibilidade: "empreender algo mediante a educação e o esclarecimento." Com a expressão Kantiana, 'esclarecimento', Adorno (2011) traz à tona a discussão da educação como sendo a que possui o potencial transformador de retirar o homem da zona de conforto de deixar que outros pensem por ele. A educação pode levar 
à autorreflexão crítica, na qual o indivíduo não se contenta com a auto inculpável menoridade, lembrando, mais uma vez, Kant (1985).

É perante essa possibilidade que pautamos nossos estudos e esforços, na tentativa de fortalecer a consciência individual - sem perder de vista o bem coletivo - e a autonomia para pensar. Sendo assim, desenvolver a aptidão para a experiência é antes de tudo pensar que o indivíduo é capaz de formular os próprios conceitos, sobretudo, para os fins deste trabalho, no respeito às diferenças humanas e na luta contra qualquer tipo de violência.

Com o apoio da reflexão, ainda que breve, sobre 'tempo,'memória' e 'história' tratados nesta seção, discutir-se-á em seguida, mais especificamente, sobre o conceito de experiência e do resgate deste, como possível empreendedor de mudanças significativas na educação e na maneira do indivíduo se perceber na sociedade, enquanto construtor de histórias diferentes das que oprimem, segregam e violentam.

\title{
O empobrecimento da experiência e os desafios da educação inclusiva
}

Em um diálogo 4 entre Adorno e Becker, no texto 'Educação - Para quê', no livro Educação e Emancipação ${ }^{5}$, ambos concordam que a falta de aptidão à experiência tem influência direta no nível qualificado de reflexão:

\begin{abstract}
Becker - Por esta via nos acercamos de uma interessante questão. As tarefas que há pouco atribuíamos à educação já não são mais atribuições de alguma formação superior - mas elas também se colocam em planos que, vistos pelas representações hierárquicas da formação, situam-se mais embaixo. Justamente na formação profissional do trabalhador necessita-se uma aptidão à experiência desenvolvida e um elevado nível de reflexão, para preservar-se em situações em permanente transformação e suportando aquilo que o senhor designou como "pressão do mundo administrado". (ADORNO, 2011, p. 150).
\end{abstract}

Posto isto, percebe-se uma linha tênue entre reflexão e experiência, nesse sentido, para que a reflexão seja possível. Há que se formar

4 "Debate na Rádio de Hessen; transmitido em 26 de setembro de 1966; publicado em Neue Sammlung, janeiro/fevereiro de 1967." (ADORNO, 2011, p. 188).

5 Referência completa no final deste trabalho. 
por intermédio da experiência de maneira mútua. Nessa perspectiva da educação, os autores procuram expor que a valorização da experiência deveria ocorrer em todo o conjunto da estrutura educacional e em todas as formas de educação, como sinaliza Becker. No entanto, o que se percebe no atual estágio civilizatório é que a experiência está em declínio e uma das causas identificadas por Benjamin (1987, p. 197) em 'O narrador. Considerações sobre a obra de Nikolai Leskov' é que a "arte de narrar está em vias de extinção.".

A arte de narrar se encontra estreitamente interligada ao conceito de experiência. Intercambiar experiências, faculdade, que, segundo Benjamin (1987, p. 198),parecia segura e inalienável, está em decadência: "Uma das causas desse fenômeno é óbvia: as ações da experiência estão em baixa, e tudo indica que continuarão caindo até que seu valor desapareça de todo." Se a capacidade de narrar está se extinguindo, da mesma maneira, o autor alerta para o desaparecimento do 'dom de ouvir'. Não há o que narrar, mas caso haja, também não tem quem ouça: "Não se percebeu devidamente até agora que a relação ingênua entre o ouvinte e o narrador é dominada pelo interesse em conservar o que foi narrado. Para o ouvinte imparcial, o importante é assegurar a possibilidade da reprodução." (Ibidem, p. 210).

A experiência é comprimida na sociedade burguesa capitalista. $\mathrm{O}$ que se faz atualmente no cotidiano da vida que seja digno de ser narrado? O que marca a subjetividade do indivíduo, de tal maneira que se consiga rememorar um mês depois? É possível lembrar o que foi comido na terça-feira da semana passada?

A facilidade de narrar experiência é algo comum entre os narradores:

Comum a todos os grandes narradores é a facilidade com que se movem para cima e para baixo nos degraus de sua experiência, como numa escada. Uma escada que chega até o centro da terra e que se perde nas nuvens - é a imagem de uma experiência coletiva, para a qual mesmo o mais profundo choque da experiência individual, a morte, não representa nem um escândalo nem um impedimento. (BENJAMIN, 1987, p. 215).

Onde se esconde essa facilidade em narrar? Quem se sente apto a narrar uma experiência sobre o ofício cotidiano de ensinar? Benjamin (1987, p. 201) aponta dois fortes concorrentes ao estado atual de deca- 
dência em que se encontra a narrativa de experiências: o romance e a informação. Quanto ao primeiro - o romance - surge no início do período moderno e se distingue da narrativa, primeiramente, porque se vincula ao livro e sua difusão acontece a partir da invenção da imprensa, se desconecta, pois da tradição oral. Outra importante diferença é que "A origem do romance é o indivíduo isolado, que não pode mais falar exemplarmente sobre suas preocupações mais importantes e que não recebe conselhos nem sabe dá-los." A informação, por sua vez, acontece de forma rápida e massivamente nos meios de comunicação, mal há tempo para processá-la e digeri-la.

A informação já chega ao receptor, acompanhada de explicação, no entanto, segundo Adorno (2011, p. 79), isso não deveria retirar o senso crítico do telespectador ou do ouvinte. Nesse sentido, o referido autor não nega que a informação seja necessária e que possa em alguma medida esclarecer fatos ou colocar em exposição pontos de vista diferentes. Rejeitar a informação não parece ser um caminho inteligente. Antes, é preciso ensinar ao telespectador a ver televisão, por mais irônico que pareça ser: "ver tevê sem ser iludido, ou seja, sem se subordinar à televisão como ideologia." Em resposta à Kadelbach sobre a explicação do que Adorno (2011, p. 80) entendia por 'televisão como ideologia', afirma:

Em primeiro lugar, compreendo "televisão como ideologia" simplesmente como o que pode ser verificado, sobretudo nas representações televisivas norte-americanas, cuja influência entre nós é grande, ou seja, a tentativa de incutir nas pessoas uma falsa consciência e um ocultamento da realidade, além de, como se costuma dizer tão bem, procurar-se impor às pessoas um conjunto de valores como se fossem dogmaticamente positivos, enquanto a formação a que nos referimos consistiria justamente em pensar problematicamente conceitos como estes que são assumidos meramente em sua positividade, possibilitando adquirir um juízo independente e autônomo a seu respeito. Além disto, contudo, existe ainda um caráter ideológico-formal da televisão, ou seja, desenvolve-se uma espécie de vício televisivo em que por fim a televisão, como também outros veículos de comunicação de massa, converte-se pela sua simples existência no único conteúdo da consciência, desviando as pessoas por meio da fartura de sua oferta daquilo que deveria se constituir propriamente como seu objeto e sua prioridade. (grifo nosso). 
Optou-se por referenciar longamente esse trecho para demonstrar a concepção de Adorno quanto aos meios de comunicação de massa e, por conseguinte, o caráter informacional que os meios de comunicação podem adquirir em um movimento dialético que pode formar, mas também, deformar.

No trecho destacado, parece um tanto quanto objetivo o pensamento do autor, a adesão cega aos meios de comunicação, sem o senso crítico, pode idealizar relações e vínculos humanos. Idealizam-se, a partir de novelas e séries, amores que não existem, famílias perfeitas, pessoas estereotipadas no seu físico, ações e sentimentos.

Nesse contexto, o professor, por sua vez, idealiza o estudante e a turma que gostaria de ter. Romantiza o processo de ensino-aprendizagem e sente medo de enfrentar os desafios, mas reprime o medo e não o vive em seu potencial. Quanto ao medo reprimido, Adorno (2011, p. 128), enfatiza:

Tanto é necessário tornar consciente esse mecanismo quanto se impõe a promoção de uma educação que não premia a dor e a capacidade de suportá-la, como acontecia antigamente. Dito de outro modo: a educação precisa levar a sério o que já de há muito é do conhecimento da filosofia: que o medo não deve ser reprimido. Quando o medo não é reprimido, quando nos permitimos ter realmente tanto medo quanto esta realidade exige, então justamente por essa via desaparecerá provavelmente grande parte dos efeitos deletérios do medo inconsciente e reprimido. Pessoas que se enquadram cegamente em coletivos convertem a si próprios em algo como um material, dissolvendo-se como seres autodeterminados. Isto combina com a disposição de tratar outros como sendo uma massa amorfa. Para os que se comportam dessa maneira utilizei o termo "caráter manipulador" em Auihoritarian personality (A personalidade autoritária) [...]. (grifo nosso).

O sentimento de medo, em vez de ser um impulso para viver a experiência, pelo contrário, é reprimido e negado, o que gera efeitos degradantes, já destacados por Adorno (2011), tais como uma geração de seres autodeterminados e sem autonomia que não se identificam com o outro. Há, por esta via, uma repulsa ao perceber o outro como uma massa amorfa, assim, justifica-se a dita incapacidade do estudante de 
aprender, ao buscar o estudante ideal, o qual não condiz com a realidade. O que foge ao padrão idealizado é dispensado, esquivando-se, desta maneira, da possibilidade de viver a experiência de aprender junto, conhecer o novo e sair da falsa imaginação de que o professor já sabe tudo.

A educação inclusiva se encontra no bojo dessa discussão. Quando se assume que o estudante tem uma deficiência e, em muitos dos casos, apresenta necessidades educacionais especiais, o professor, muitas vezes, o repulsa em um movimento de aversão. Ao contrário da política ${ }^{6}$ da educação na perspectiva da educação inclusiva que se tem hoje $^{7}$, antes, os estudantes com deficiência encontravam-se em escolas especiais.

Esse processo foi necessário e pertinente naquele momento, a intenção não é julgá-lo, visto que foi necessário para que se chegasse na concepção da educação na perspectiva inclusiva que vive-se atualmente. No entanto, a pergunta que se coloca é: uma turma de estudantes com a mesma deficiência atende aos estímulos educacionais da mesma maneira? Esse parece ser o primeiro nó da questão e nessa medida parece insustentável a segregação.

Quando se pergunta: uma turma de estudantes sem deficiência atende aos estímulos educacionais da mesma maneira? A resposta para as perguntas se assemelha e gera uma reflexão necessária. Se cada qual é diferente na constituição da individualidade, a maneira de aprender não poderia ser muito diferente disso.

Posto isto, quando a discussão gira em torno da educação inclusiva, a reflexão, sem dúvida é sobre a educação geral. O professor precisa refletir para qual estudante ele se sente preparado. Se sentir preparado já teria por si só algo de retrógrado, na medida em que a aptidão à experiência habilita ao aprendizado junto e ao enfrentamento dos desafios. Nesse contexto, pode-se dizer que tem habilitação para desenvolver determinado ofício, mas estar preparado não é um estado estático e sim uma busca cotidiana de aperfeiçoamento que perpassa pela coragem e ousadia de fazer diferente todos os dias.

6 BRASIL. Ministério da Educação. Secretaria de Educação Especial. Política Nacional da Educação Especial na perspectiva da Educação Inclusiva. Brasília: MEC/SEESP, 2008.

7 Ver também o Decreto no 7.611, de 17 de Novembro de 2011. Dispõe sobre a Educação Especial, o Atendimento Educacional Especializado e dá outras providências. Presidência da República, Casa Civil, Subchefia para Assuntos Jurídicos. Brasília, DF. Disponível em: <http:// www.planalto.gov.br/ccivil_03/_ Ato2011-2014/2011/Decreto/D7611.htm> Acesso em: 20 de jun. de 2012. 
Conforme já visto anteriormente, experiência e vivência denotam em Walter Benjamin um par conceitual distinto, embora a vivência possa ser incorporada à experiência:

De acordo com Konder (1999, p. 83), Benjamin utilizava Erfahrung para falar do conhecimento adquirido através de uma experiência acumulada, prolongada, desdobrada, num sentido próximo à "viagem" (que em alemão é fahren). Por sua vez, nos textos dos anos 1930, o filósofo marxista retoma a questão da experiência sob uma nova perspectiva: a Erfahrung em oposição à Erlebnis, que corresponde à vivência, do indivíduo solitário, privado, isolado. A Erlebnis (e cabe ressaltar que a Erfahrung não a exclui, mas a pressupõe e ultrapassa) é a forte impressão, que exige uma assimilação às pressas e que produz efeitos instantâneos. (REBUÁ, 2015, p. 315).

No sentido que procuramos expor, a experiência deixa marcas que passam a pertencer à subjetividade do indivíduo. As marcas deixadas constituem o eu interior, a maneira de ser e agir e pode humanizar o olhar para perceber nas tessituras do convívio social que há sempre o que aprender com o outro. A pergunta que se coloca nesse sentido é: será que o professor vive experiências com os estudantes ou apenas vivências diárias que não têm o potencial de modificar nem a ele e tampouco ao estudante? Quanto à experiência comunicável, Benjamin (1987, p. 114) afirma:

Sabia-se exatamente o significado da experiência: ela sempre fora comunicada aos jovens. De forma concisa, com a autoridade da velhice, em provérbios; de forma prolixa, com a sua loquacidade, em histórias; muitas vezes como narrativas de países longínquos, diante da lareira, contadas a pais e netos.

Onde estão esses lugares diante das lareiras? Onde estão esses jovens que paravam a vida corrida para ouvir uma história contada pelos avós? Qual autoridade é essa que a velhice confere? Benjamin (1987, p. 114) enfatiza:

Não, está claro que as ações da experiência estão em baixa, e isso numa geração que entre 1914 e 1918 viveu uma das mais terríveis experiências da história. Talvez isso não seja tão estranho como parece. $\mathrm{Na}$ 
época, já se podia notar que os combatentes tinham voltado silenciosos do campo de batalha. Mais pobres em experiências comunicáveis, e não mais ricos.

O empobrecimento da experiência afeta de maneira contundente a formação do professor. No que se refere à educação inclusiva, procuram-se respostas prontas de 'como ensinar para o estudante com determinada deficiência?' O fato é que a resposta dificilmente será igual sempre. Pensar o 'como' é necessário, mas são os 'meios' No entanto, pensar a finalidade da educação para além dos 'meios' já seria por si só um avanço na formação.

De acordo com Agra (2015), a formação do professor é frágil, sobretudo pela inaptidão à experiência. Não se trata de culpar o professor. Antes, a intenção é propiciar uma reflexão acerca dos mecanismos utilizados pela sociedade capitalista para que o professor e a formação se fragilizem de tal maneira que o professor se veja como incapaz de ensinar ao aluno 'a' ou 'b', ou se justifique ao narrar que se sente despreparado para atuar com o aluno ' $x$ ' ou ' $y$ '.

Se a experiência tem tamanha importância no cenário educacional e na constituição do indivíduo como pessoa, por que a inaptidão de viver experiências? Benjamin (1987, p. 115) para essa questão possibilita algumas linhas de pensamento, como a que afirma 'o monstruoso desenvolvimento da técnica, ao sobrepor-se ao homem, empobrece a experiência':

Aqui se revela, com toda clareza, que nossa pobreza de experiências é apenas uma parte da grande pobreza que recebeu novamente um rosto, nítido e preciso como o do mendigo medieval. Pois qual o valor de todo o nosso patrimônio cultural, se a experiência não mais o vincula a nós? A horrível mixórdia de estilos e concepções do mundo do século passado mostrou-nos com tanta clareza aonde esses valores culturais podem nos conduzir, quando a experiência nos é subtraída, hipócrita ou sorrateiramente, que é hoje em dia uma prova de honradez confessar nossa pobreza. Sim, é preferível confessar que essa pobreza de experiência não é mais privada, mas de toda a humanidade. Surge assim uma nova barbárie.

É possível perceber que o desenvolvimento humano não acompanha o desenvolvimento tecnológico. O desenvolvimento humano fi- 
cou para trás, enquanto se buscava entender a nova tecnologia lançada. O trabalho era desenvolvido com e entre homens. Agora o trabalho é do homem solitário com uma máquina. Quais os efeitos dessa realidade que se apresenta? Para Benjamin (1987, p. 115):

Barbárie? Sim. Respondemos afirmativamente para introduzir um conceito novo e positivo de barbárie. Pois o que resulta para o bárbaro dessa pobreza de experiência? Ela o impele a partir para frente, a começar de novo, a contentar-se com pouco, a construir com pouco, sem olhar nem para a direita nem para a esquerda. Entre os grandes criadores sempre existiram homens implacáveis que operaram a partir de uma tábula rasa. Queriam uma prancheta: foram construtores.

Ser construtor, partir da tábula rasa e construir com pouco é essa capacidade do homem que parece ter caído no esquecimento. Para Adorno (2011, p. 155): "O problema que se impõe nesta medida é saber se por meio da educação pode-se transformar algo de decisivo em relação à barbárie."Tanto Adorno (2011) quanto Benjamin (1987) fazem referência ao conceito de barbárie. Adorno (2011, p. 155) se arrisca e explica o que entende como barbárie:

Entendo por barbárie algo muito simples, ou seja, que, estando na civilização do mais alto desenvolvimento tecnológico, as pessoas se encontrem atrasadas de um modo peculiarmente disforme em relação a sua própria civilização - e não apenas por não terem em sua arrasadora maioria experimentado a formação nos termos correspondentes ao conceito de civilização, mas também por se encontrarem tomadas por uma agressividade primitiva, um ódio primitivo ou, na terminologia culta, um impulso de destruição, que contribui para aumentar ainda mais o perigo de que toda esta civilização venha a explodir, aliás, uma tendência imanente que a caracteriza. Considero tão urgente impedir isto que eu reordenaria todos os outros objetivos educacionais por esta prioridade.

Reordenar os objetivos educacionais é uma das pistas deixadas por Adorno (2011). Os professores se encontram cansados. Viver experiências, como dito anteriormente, necessita de tempo. Para onde foi o tempo? A tecnologia que no lampejar do sonho humano consistiria em dar ao trabalhador mais tempo, pelo contrário, o tira até o último minu- 
to. A sociedade capitalista tem pressa. As respostas precisam ser imediatas e os efeitos são instantâneos.

Segundo Benjamin (1987, p. 118), a pobreza de experiência não significa, necessariamente, a ignorância do homem. Talvez ele sinta algo estranho, sinta a falta de algo, mas encontra-se cansado. É mais fácil se deixar levar pela grande onda em direção à destruição: "Ao cansaço segue-se o sonho, e não é raro que o sonho compense a tristeza e o desânimo do dia, realizando a existência inteiramente simples e absolutamente grandiosa que não pode ser realizada durante o dia, por falta de forças." A cultura imposta é a da solidão, quem sobreviverá a essa cultura? Difícil responder. Humanizar o humano, quem diria que seria necessário? Ainda há esperança. É preciso resistir, lutar, transformar e se transformar em humano. Ser indivíduo, único, real, pleno e diferente. Benjamin (1987, p. 119) não desiste de desejar que a humanidade sobreviva à cultura e que o faça sorrindo: "Talvez esse riso tenha aqui e ali um som bárbaro. Perfeito. No meio tempo, possa o indivíduo dar um pouco de humanidade àquela massa, que um dia talvez retribua com juros e com os juros dos juros".

Nesse contexto, potencializar o indivíduo e oferecer instrumentos para desenvolver a racionalidade e o senso crítico da realidade é a possibilidade real de promover uma sociedade justa. A educação, posta em Adorno (2011, p. 182), é uma educação que caminha lado a lado da emancipação e é nesse ponto que se precisa direcionar os esforços: "[...] a única concretização efetiva da emancipação consiste em que aquelas poucas pessoas interessadas nesta direção orientem toda a sua energia para que a educação seja uma educação para a contradição e para a resistência." Assim, a educação será pensada 'sob medida' para o estudante. Qual estudante? O estudante que tem o direito de ser único, singular, pessoa, indivíduo e diferente, independente de ter deficiência ou não.

Vale ressaltar que a educação com vistas à emancipação não nega a adaptação, pois esta é necessária para o indivíduo se orientar no mundo, porém não deveria ser a finalidade da educação. A educação visando à emancipação não exclui a adaptação, mas também não se finda nela; a emancipação compreende a adaptação e a supera. Assim, a educação, ao visar à emancipação, tem relação com a educação inclusiva. Segundo Agra (2015, p. 20):

[...] o que a educação visando à emancipação tem a ver com a educação inclusiva? A educação ao ter por objetivo a emancipação dos indivíduos estará 
mais aberta à diversidade humana e às diferenças inerentes ao ser humano. Consequentemente, os indivíduos serão mais sensíveis a viver experiências diversas sem antes julgar ou menosprezar os que não se enquadram nos modelos ideais de homem. Nesta perspectiva, a educação terá a força necessária para combater a manifestação do preconceito produzida, sobretudo, por pensamentos estereotipados e acríticos.

Posto isto, ao retomar a questão inicial deste trabalho: "Para que viver experiências na formação de professor?" Após o exposto, a resposta parece óbvia ou não. Longe de ter uma resposta pronta ou uma receita de 'como fazer', propõe-se aqui a reflexão e a prioridade é resistir ao horror de fazer mais do mesmo: excluir, segregar, alienar e alienar-se. Adorno (2011) considera a experiência formativa dialética como possibilidade desde que não seja desvinculada da razão.

O processo produtivo influencia diretamente o processo formativo. Isto está posto, as relações sociais podem humanizar, mas também podem gerar dominação. É preciso a racionalidade convertida no sensível de perceber no outro e em nós, a possibilidade de mudança e de transformação humana e cultural.

A educação inclusiva pode colaborar com o processo do desenvolvimento humano tanto para o professor, que aceita o desafio de olhar para o estudante não no que pode lhe faltar, mas no que há de potencial, quanto para os estudantes, na medida em que aprendem o respeito às diferenças e têm a possibilidade de desenvolver a elevação do nível de consciência, a racionalidade e a autonomia de pensar para além das idealizações da sociedade capitalista.

\section{Considerações finais}

a pobreza de experiência que acomete atualmente toda a humanidade é um problema já identificado por Benjamin e por Adorno nos textos referenciados neste trabalho, ao perceberem no contexto histórico que viviam o declínio da experiência e a antevisão do que podia acontecer de pior. Esse estudo se propôs a desenvolver uma reflexão crítica em torno da inaptidão de se viver a experiência na conjuntura da sociedade de classes e em que medida esse fato pode influenciar na formação do professor. 
Sendo assim, é possível afirmar que ao se identificar as causas que tornam a formação do professor frágil, vislumbra-se a possibilidade de conscientização e elevação do nível de consciência. A resistência às amarras degradantes tão bem forjadas na sociedade capitalista é uma escolha que gera responsabilidade e que ao mesmo tempo permite o sonho e o desejo de transformação educacional, humana e social.

Portanto, a luta deve continuar com os 'pés no chão e a cabeça erguida', ao se permitir desejar uma educação ainda não vivida, porém possível, quando caminha lado a lado da emancipação.

\section{Referências}

ADORNO, T. W. Educação e Emancipação. São Paulo: Paz e Terra, 2011. AGRA, Michelli. Democratização da Educação na Escola Pública: inclusão de estudantes com deficiência visual. Dissertação [Mestrado em Educação] - Faculdade de Educação, Programa de Pós-Graduação em Educação, Universidade Federal Fluminense, 2015, 168 p.

BENJAMIN, Walter. Magia e técnica, arte e politica: ensaios sobre literatura e historia da cultura (Obras escolhidas v. 1). $3^{\circ}$ ed. São Paulo: Editora Brasiliense, 1987.

. O capitalismo como religião. São Paulo: Boitempo, 2013.

BRASIL. Decreto n' 7.611. Presidência da República, Casa Civil, Subchefia para Assuntos Jurídicos, Brasília, DF. 2011.

CROCHÍK, José Leon. Preconceito e Inclusão. In: CROCHÍK, José Leon (coordenador). Preconceito e Educação Inclusiva. Brasília: SDH/PR, p. 65-78, 2011.

CROCHÍK et al. Atitudes de professores em relação à Educação Inclusiva. In: CROCHÍK, José Leon (coordenador). Preconceito e Educação Inclusiva. Brasília: SDH/PR, p. 193-217, 2011.

CROCHÍK J. e CROCHÍK N. Teoria Crítica e Educação Inclusiva. In: CROCHÍK, José Leon (coordenador). Preconceito e Educação Inclusiva. Brasília: SDH/PR, p. 111-125, 2011.

GAGNEBIN, Jeanne Marie. (1987). Walter Benjamin ou a história aberta. [Prefácio]. In: BENJAMIN, Walter. Magia e técnica, arte e politica: 
ensaios sobre literatura e historia da cultura (Obras escolhidas v. 1). 3. ed. São Paulo: Editora Brasiliense, 1987.

KANT, Immanuel. "Resposta à pergunta: Que é 'esclarecimento'? (Aufklarung)" In: KANT, Immanuel. Textos seletos. Petrópolis: Vozes, 1985.

REBUÁ, Carlos Eduardo. O empobrecimento e o isolamento da experiência. In: REBUÁ, Carlos Eduardo. Da praça ao solo: um novo chão para a universidade. As experiências das universidades populares de Madres de Plaza de Mayo [UPMPM] e Movimento dos Trabalhadores Rurais sem Terra [ENFF] em tempos de crise neoliberal na América Latina [2000-2010]. Tese [Doutorado em Educação] - Faculdade de Educação, Programa de Pós-Graduação em Educação, Universidade Federal Fluminense. p. 315-326, 2015. 